\title{
Carrier testing in children: exploration of genetic health professionals' practices in Australia
}

\author{
Danya F. Vears, M Genet Couns' ${ }^{1}$ Clare Delany, M Physio, PhD ${ }^{2,3}$ and Lynn Gillam, MA, PhD ${ }^{1,2}$
}

\begin{abstract}
Purpose: Despite genetic health professionals routinely providing carrier testing in adults, carrier testing in unaffected children after a sibling is diagnosed with a genetic condition remains controversial. The majority of international guidelines addressing genetic carrier testing in children recommend against providing this testing, yet little is known about current practice. This study aimed to determine whether genetic health professionals receive requests for carrier testing in unaffected children from parents of children with genetic conditions and whether they provide this testing.
\end{abstract}

Methods: Semistructured interviews were conducted with 17 Australian genetic counselors and clinical geneticists and analyzed using inductive content analysis.

Results: The genetic health professionals indicated that some parents do request carrier testing in their children, often after the diagnosis of a genetic condition in another child. Although all interviewees stated they initially advise against carrier testing, if the parents persist with their requests, then testing is occasionally provided. They indicated they consider factors such as the maturity of the child, anxiety of the parents, and potential medical benefit to make clinical judgments about when testing is appropriate, rather than relying solely on guidelines.

Conclusion: This study sheds light on current practices in carrier testing for children, validating this as an area that still requires attention.

Genet Med advance online publication 18 September 2014

Key Words: children; clinical geneticists; ethics; genetic counselors; genetic testing; parents

\section{INTRODUCTION}

Genetic health professionals routinely provide preconception and prenatal genetic carrier testing for adults. When a child is diagnosed with a genetic condition, such as cystic fibrosis (CF) or Duchenne muscular dystrophy (DMD), a genetic counselor or clinical geneticist will typically offer "cascade testing" to parents and first-degree adult relatives to determine if they are carriers. However, carrier testing of children when a sibling has a genetic diagnosis is still considered controversial.

If parents wish to know the carrier status of their unaffected children because one or more of their children are affected, they must ask a genetic health professional for testing. Until recently, the majority of guidelines developed by genetics groups worldwide recommended that carrier testing not be performed in children. ${ }^{1-4}$ These recommendations are commonly based on two perceived ethical concerns: (i) removal of the child's right to make an autonomous decision about carrier testing in the future $^{5-7}$ and (ii) possible harms to the child from testing, including adverse impacts on social, psychological, and emotional well-being that may affect perceptions of health, selfimage, and self-esteem, $, 5,6,9$ and potential stigmatization and discrimination based on carrier status. ${ }^{5-9}$

The British Medical Association (BMA), however, recently revised its recommendations to suggest that parents "seeking carrier testing for their children should be encouraged to wait until the child or young person is sufficiently mature to make a personal decision but if, after discussion, they feel testing now is important and in the best interests of their child - and there are no other factors that might indicate that testing would be harmful - testing should be permitted." 10

The BMA states that these recommendations are based on the fact that carriers are now commonly identified through preconception screening or incidentally through newborn screening, and on the belief that, because of a lack of evidence of harm from carrier testing in children, parents are best placed to make decisions for their children regarding carrier testing. ${ }^{10}$

There are three important gaps in the literature regarding carrier testing in children. The first relates to the minimal research investigating the impact of carrier testing in children, as highlighted by the BMA. ${ }^{10}$ The second gap concerns the parental perspective, with very few studies investigating parents' interest in carrier testing for their unaffected children. The final gap pertains to genetic health professionals practices when parents request carrier testing for their children. Although a number of studies have determined health professionals' hypothetical views about providing carrier testing to children, ${ }^{11-14}$ one might argue these are not indicative of actual practice. Only three studies, undertaken in the United Kingdom (2000), Europe (2007), and the United States (2007), have investigated genetic health professionals' practices in providing genetic carrier testing in

${ }^{1}$ Centre for Health and Society, Melbourne School of Population and Global Health, University of Melbourne, Parkville, Australia; ${ }^{2}$ Children's Bioethics Centre, Royal Children's Hospital, Parkville, Australia; ${ }^{3}$ School of Health Sciences, University of Melbourne, Parkville, Australia. Correspondence: Danya F. Vears (d.vears@student.unimelb.edu.au) 
minors, including carrier testing for chromosomal rearrangements and autosomal recessive and X-linked conditions. All three indicate that testing does take place. ${ }^{11,15,16}$ However, these studies provide no insight into the circumstances in which carrier testing is performed, or whether testing is performed in response to requests by the parents or recommendations by the health professionals. They also used survey-based methods, which limited the potential for exploration of the reasons behind health professionals' decisions to provide testing in children.

This study has two aims. The first is to determine whether genetic health professionals receive requests for carrier testing in unaffected children from parents of children with genetic conditions. The second is to examine how they respond to these requests, including whether and why they provide testing.

\section{MATERIALS AND METHODS}

This study utilized a qualitative methodology drawing on a social constructivist framework ${ }^{17}$ and involving key informant interviews. ${ }^{18}$ It explored genetic health professionals' experiences of receiving requests from parents for carrier testing in their healthy children and their responses to such requests. The research design allowed for the participants to provide both descriptions and interpretations of their practice as a form of data. This study was approved by the University of Melbourne Human Research Ethics Committee (ID 1137204).

Purposive sampling was used. Genetic health services were asked to nominate genetic health professionals likely to have the most experience of receiving requests for carrier testing in children, based on their involvement in pediatric genetic testing. Genetic health professionals with less than 3 years of experience were excluded. Participants were invited by e-mail and subsequent telephone contact to determine interest. Seventeen genetic health professionals participated in the study, with at least one from each state and territory in Australia, comprising 10 genetic counselors and 7 clinical geneticists, 11 (65\%) of whom were female. The health professionals had a mean of 14.4 years of experience in their respective professions (range, 8-25 years) and 13.2 years in the pediatric genetic setting (range, 6-25 years).

Participants were interviewed in person or over the telephone using a semistructured interview schedule. They were asked about two areas: (i) their experiences of receiving requests from parents for carrier testing of their children, including the frequency of requests and the conditions and contexts in which requests occurred; and (ii) how they respond to these requests, including whether they ever provide carrier testing for these children and how they make decisions about testing. The term "children" was deliberately left undefined, allowing participants to comment on mature and immature minors as they deemed appropriate. Interviews were audiorecorded and ranged between 30 and 70 minutes (mean, 48 minutes).

The interviews were transcribed verbatim and analyzed using inductive content analysis, in which content categories are derived from the data (rather than predetermined). ${ }^{19-21}$ Each transcript was coded into broad content categories. Then, sections of the data within the broad categories were compared and more specific subcategories were developed. All interviews were coded by D.F.V.; L.G. and C.D. coded a subset to confirm the coding scheme.

\section{RESULTS}

The results are reported in two sections corresponding to the two research questions:(i) experiences of requests and (ii) responses to requests. Representative quotations and the profession of the interviewee are provided. There were no discernible differences between the practices of genetic counselors and clinical geneticists.

\section{Experiences of requests}

Participants' comments about their experiences of receiving requests for carrier testing demonstrate variation in parents' desires for this type of testing. The most commonly mentioned condition was CF, with 13 of 17 (76\%) health professionals recalling receiving requests from parents. Fragile X syndrome $(11 / 17 ; 65 \%)$, DMD $(8 / 17 ; 47 \%)$, and spinal muscular atrophy $(7 / 17 ; 41 \%)$ were also mentioned as more frequently requested conditions, with a range of other genetic conditions less frequently requested (see Figure 1).

The majority of genetic health professionals (10/17; 59\%) reported that requests from parents for carrier testing in their children were infrequent. A small proportion, (5/17; 29\%) indicated that they encountered these requests much more frequently. Three genetic health professionals indicated that during a consultation with parents of an affected child, they state upfront that carrier testing of the unaffected children is not recommended, an approach that possibly discourages parents from articulating a desire for testing.

It really doesn't happen for us very often, and I think a lot of it has got to do with the counseling that's done and the communication that's done on diagnosis or shortly thereafter. (interview 7 , genetic counselor)

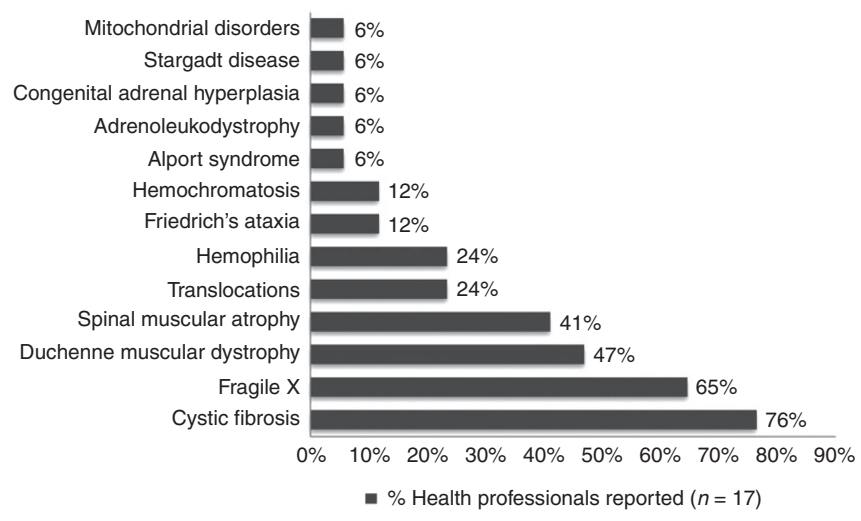

Figure 1 Percentage of health professionals who reported parents requesting carrier testing in their healthy children for specific genetic conditions. 
Participants cited the two most common contexts in which carrier testing is requested by parents as (i) when one child or another family member has been diagnosed with a genetic condition and (ii) when a child is identified as a carrier of CF via a newborn screening test and parents request carrier testing for their other children. These requests commonly occur around the time of diagnosis/carrier identification or once the initial shock of diagnosis has subsided.

If one of the kids has recently been diagnosed as something then the question will come up ... what about my other children? How do I know if they're carriers or not? (interview 14, clinical geneticist)

Participants reported that the initial request for carrier testing did not appear to be dependent on the age of the other children. Rather, parental requests arose if there were concerns about carrier status or concerns for their unaffected child's health. Requests may also occur when the child is in his or her adolescent or late teenage years.

The other time that it would come up would be the issue of how do you define when a child is getting towards the end of the teenage years and sexually active teenagers and parents wanting to get carrier status sorted out for, you know, 15-, 16-year-olds. (interview 6, genetic counselor)

These requests are often prompted by the child becoming sexually active or likely to become so in the near future and parents wanting them to be informed for reproductive decision making.

\section{Health professionals' responses to requests}

In response to parents' requests for carrier testing in their healthy children, all participants reported that they initially discourage or recommend against carrier testing. Discouragement was often placed in the context of a detailed discussion to ensure that parents were fully informed about the reasons why testing is not normally performed in children. Participants described how the discussion often included explanations about protection of the children's future autonomy and right to decide for themselves whether they want to know their carrier status.

Our practice is to avoid it and to use counseling skills to encourage families to think about the fact that it's not necessary. (interview 2 , genetic counselor)

We say that it's something that we prefer that they [children] are involved in themselves when they're old enough to be informed about that. (interview 5, genetic counselor)

The majority of health professionals indicated that after discussion, most parents are content not to test. However, according to participants, some parents persist in their request for carrier testing of their child. When this occurs, health professionals differ in their responses. Some health professionals continue to refuse to facilitate testing for the family.

In general we don't offer it to children ... not sort of saying absolutely not, we won't do it, but at the same time, we won't. (interview 16, genetic counselor)

Some health professionals may facilitate testing in the unaffected child but have a high threshold, in that parents have to be very determined for the professional to agree to testing taking place.

Occasionally we get people who are adamant that they want to have their child tested ... and I mean, yeah, occasionally we have tested in that circumstance. (interview 11, clinical geneticist)

Other health professionals seem to have a much lower threshold for testing, and parents do not need to be as forceful to have their unaffected child tested.

Look, if a parent did take their request further, we would usually be happy to-talking about cystic fibrosis-we're usually happy to carry out testing. (interview 4 , genetic counselor)

\section{Reasons behind facilitating carrier testing}

Genetic health professionals described factors they considered when making decisions about performing carrier testing. These fell into three main categories.

Qualities of the child. Some health professionals regarded a display of adult-like behaviors in the child as an indication in favor of testing.

If they're still officially children but acting in an adult manner-so living away from home, you know, partner, sexually active, displaying other sorts of mature characteristics and express that desire-then that may, would be considered then. (interview 14, clinical geneticist)

Other factors, such as the children's understanding of the discussion and whether they requested the test themselves, were also raised as aspects that the genetic health professionals consider when deciding about providing testing.

Yeah, their maturity, so how mature they are, how able you are to engage them in a discussion about it, what kind of reasons they can put forward as to why they want to know. (interview 6, genetic counselor)

The family context. Some health professionals indicated they consider a family history of a genetic condition, especially when 
the condition has an ongoing impact on the family, as counting in favor of providing carrier testing in healthy children.

Yeah sure, I mean if they've got a sibling with cystic fibrosis then they know ... what it is to have cystic fibrosis and what it means, you know, if they're a carrier and their partner's a carrier then they understand that better than a person who's picked up ... in population screening who's never seen the condition. (interview 15, clinical geneticist)

Health professionals took note of parental anxiety; some felt parental anxiety was not a sufficient reason to provide testing, whereas others acknowledged that not providing testing might be harmful and disruptive for some families and therefore would provide testing if parents were anxious.

At the end of the day we aim for the families to function as a family, and resisting carrier testing or even delaying carrier testing for these families was actually being quite destructive. (interview 10, genetic counselor)

Parents' reasons for wanting to know and how much they had reflected on the decision to test were additional considerations.

Potential benefit and what is at stake. Some health professionals said that potential health implications or medical benefit from carrier testing might factor into decisions of whether to facilitate testing. Differences between carriers of autosomal recessive and X-linked conditions, in which females may have some health implications, were highlighted. Yet some commented that the greater reproductive implications for female carriers of X-linked conditions, apart from any health impacts, might influence their decision making.

I think disorders that do have clinical implications in childhood in the female, then yeah, I would feel comfortable testing for those. (interview 11, clinical geneticist) I think recessive conditions, I think it's much more straightforward than X-linked ones where there are more significant implications for carriers. (interview 1, genetic counselor)

\section{DISCUSSION}

This is the first empirical study to explore genetic health professionals' descriptions of their current practices in response to parental requests for carrier testing in children in Australia. It is also the first study to assess practices regarding carrier testing to be published worldwide since 2007. This 6-year gap is likely to reflect considerable changes in practice due to the rapidly evolving nature of genetic medicine.

The study showed that although requests are not common, some parents want to know the carrier status of their other children, particularly when one child has been diagnosed with a genetic condition. This is similar to other studies that suggest that between 44 and $91 \%$ of parents of children with CF, ataxia telangiectasia, chromosomal translocations, or deafness want to know the carrier status of their other children. ${ }^{22-25}$

The genetic health professionals reported CF, fragile X syndrome, DMD, and spinal muscular atrophy as the most common conditions for which carrier testing was requested. This was in line with the 2007 European study in which $34 \%$ of clinical geneticists had previously provided carrier testing in minors (younger than 16 years) for CF, 36\% had provided it for fragile X syndrome, and $28 \%$ had provided it for DMD. ${ }^{11}$ This is a reflection of these being relatively common childhood-onset conditions. $^{26-29}$

Initial recommendations by genetic health professionals against carrier testing in response to parental requests aligned with guidelines produced by the Human Genetic Society of Australasia (HGSA) - which state "minors should only have carrier testing performed when the resulting information will be used to help with their health management in the immediate future"-and the majority of international bodies addressing carrier testing in children. ${ }^{1-4,10,30}$ The finding that some parents persist with requests and receive testing is important because previous studies have not distinguished between carrier testing driven by parental requests and medical recommendations. ${ }^{22,31,32}$

This study identified surprising differences in the reported frequency of parental requests for carrier testing in their children. The interview process uncovered variation in what counts as a request for testing, with one interpretation being that a simple expression of interest constitutes a request and another being that only a more formal and specific request for carrier testing does so. This disparity in genetic health professionals' interpretations of requests may account for some of the variation in reported frequencies, a finding that would not have been identified had a structured survey been used, rather than taking an inductive approach..$^{33}$ Importantly, preemptive discussions recommending against carrier testing in children may have reduced the number of requests in services that address carrier testing in that manner. Therefore, we cannot infer how many parents want testing directly from how many actually request it.

Before this study, very little was known about the factors that genetic health professionals take into account when making decisions about whether to provide carrier testing for minors. This information is important because genetic health professionals effectively act as gatekeepers to this testing. An important finding in this study is the variation in genetic health professionals' reasoning about carrier testing, which has implications for consistency in availability of this service for parents. The genetic health professionals discussed the qualities the child possessed as one of these factors and in general seemed more inclined to provide carrier testing to children who displayed evidence of being a "mature minor." ${ }^{34}$ A number of the genetic health professionals considered that initiating the request was a marker of maturity or readiness for carrier testing, and other authors have postulated that this may indicate these young people are well positioned to understand the testing and its implications in order to cope with the results. ${ }^{35}$ Although the concept of mature minors is not addressed in the HGSA guidelines for 
carrier testing, it seems to influence genetic health professionals' decision making in this area.

Given that parents seem to request carrier testing in their other children around the time of diagnosis of an affected child, this is likely to be an anxious time for families. However, genetic health professionals appear to have different perspectives on whether parental anxiety is an appropriate reason to test, with some more likely to provide testing to help reduce anxiety whereas others still encourage parents to postpone testing until their children are able to decide about carrier testing for themselves. One clinical geneticist was aware of this complexity:

Part of the paradox is the more desperate they are to have the information, the more concerned you are about how they're going to deal with the information and particularly how they'll deal with it if they get the undesirable result (interview 11, clinical geneticist).

Because many siblings will be quite young, parents will likely have to wait many years to find out their children's carrier status. In addition to the anxiety this delay may cause parents, it has implications for the children because, with the passing of time, parents may lose touch with genetic services or forget to pass on information about the children's possible carrier risks. ${ }^{36}$ Previous studies, such as those by Järvinen and colleagues, have highlighted that carrier testing does not guarantee children will be informed of their reproductive risks. ${ }^{37,38}$ However, refusing testing may result in an even greater proportion of children not being informed of their carrier risk when there is no definitive result for parents to pass on.

Several participants expressed concerns regarding the lack of support for parents if they were to turn to nongenetic practitioners as an alternative source of testing. As direct-to-consumer genetic testing becomes more commonly available, it will offer parents another route to carrier testing for their children. This will pose an increasing challenge for genetic health professionals.

A small number indicated they were more comfortable facilitating testing when there was possible medical benefit. However, even for X-linked conditions such as DMD and hemophilia, ${ }^{39,40}$ the chance of a known carrier status influencing medical care in childhood is low and would not lead to "immediate medical benefit," as recommended in the HGSA guidelines. ${ }^{2}$ By contrast, some genetic health professionals seemed more likely to facilitate testing for autosomal recessive conditions, describing testing as more straightforward based on three main features: (i) no health implications for carriers; (ii) potentially lower burdens of guilt for mothers not being the sole contributors of the condition; and (iii) reduced reproductive risks for carrier children, requiring a carrier partner to have the potential of an affected child. Discussion of these factors implied they felt both parents and children should be less worried about identification of carriers of autosomal recessive than X-linked conditions, potentially making counseling more clear-cut.
Although some contrasted carrier testing with predictive testing for early-onset autosomal dominant conditions, very few mentioned the potential of carrier testing in children to lead to incidental identification of affected status. When mentioned, this was mainly for fragile $\mathrm{X}$ syndrome, for which participants discussed the difficulties of defining what constitutes a carrier and potential identification of mildly affected females. This limited discussion is likely to be attributable to the predominance of carrier testing requests for highly penetrant conditions with early onset, such as CF, with low risk of incidental identification.

When other factors such as the maturity of the children and parental anxiety are considered when deciding about carrier testing, some genetic health professionals are responding to the needs of the families rather than conforming to the guidelines. These personalized responses are more consistent with the BMA recommendations, which advocate for the parents' right to decide if carrier testing is the right option for their family, than with HGSA guidelines, which advocate preserving the child's right to future autonomy. ${ }^{10}$ However, the initial discouragement parents encounter suggests many will not have access to carrier testing for their other children, even if they are informed and feel this would be the best course of action for their family. Although carrier testing may not be appropriate for all families, presenting parents with carrier testing as an option and allowing them to choose may allow for more familyfocused rather than solely child-focused approaches to carrier testing discussions.

The main limitation of this study is the small sample size. However, genetic health professionals were accessed from all states and territories in Australia, and this sample accounts for $\sim 25 \%$ of genetic health professionals working primarily within the pediatric genetic setting. Given the lack of recent studies investigating practices of genetic health professionals worldwide, additional research to elucidate whether practices differ in other parts of the world are necessary.

In summary, this study has shown that within Australia, knowing the carrier status of their children is of interest to some parents, particularly in response to diagnosis of a genetic condition in the family. Although the genetic health professionals interviewed initially recommend against carrier testing, some do facilitate testing for these families and they make clinical judgments about when they feel testing is appropriate rather than relying solely on guidelines. The practices of at least some genetic health professionals in this study seem to be in line with the recent BMA guidelines, whereas others seem to practice in accordance with older guidelines, such as those developed by the HGSA. Although actual practice should not in itself drive the content of guidelines, when experienced genetic health professionals act in a somewhat different manner than what is recommended by their professional guidelines, it is reasonable to consider the reasons behind their practices and whether revision of guidelines is warranted. The potential for parents to access testing through direct-to-consumer companies should also be considered if new guidelines are developed. 
This study sheds light on a practice previously uninvestigated in Australia and has relevance for other countries. In relation to professional practice, it is particularly relevant for countries with similar populations and health systems. In relation to parents' motivations for requesting testing, there is not enough evidence from this study to indicate whether the cultural background of parents influences these motivations. It would be worthwhile investigating this further, both in Australia and other countries, in different cultural settings. In addition, given that the preemptive nature of the way in which carrier testing may be discussed by genetic health professionals may prevent parents from requesting testing, it would be beneficial to interview parents of children with genetic conditions to gain a better appreciation of why parents want carrier testing performed in their other children, and how readily they express this to health professionals.

\section{ACKNOWLEDGMENTS}

We thank all the genetic health professionals for their participation and John Massie for his valuable contributions to this article.

\section{DISCLOSURE}

The authors declare no conflict of interest.

\section{REFERENCES}

1. Borry P, Fryns JP, Schotsmans P, Dierickx K. Carrier testing in minors: a systematic review of guidelines and position papers. Eur J Hum Genet 2006;14:133-138.

2. Human Genetic Society of Australasia. Process of Genetic Counselling. 2008. http://www.hgsa.org.au/2011/03/process-of-genetic-counselling-2/.

3. Ross LF, Saal HM, David KL, et al. Technical report: ethical and policy issues in genetic testing and screening of children. Genet Med 2013;15:234-245.

4. Committee on Bioethics CoG, and the American College of Medical Genetics and Genomics Social, Ethical and Legal Issues Committee. Ethical and policy issues in genetic testing and screening of children. Pediatrics 2013;131:620-622.

5. American Medical Association. Testing children for genetic status. 1995 http://www.ama-assn.org/ama/pub/physician-resources/medical-ethics/codemedical-ethics/opinion2138.page.

6. Clarke A. The genetic testing of children. Working Party of the Clinical Genetics Society (UK). J Med Genet 1994;31:785-797.

7. British Medical Association. Testing of adults and children with a family history of genetic disorder. Human Genetics: Choice and Responsibility. Oxford University Press: Oxford, UK, 1998:61-99.

8. American Society of Human Genetics Board of Directors, American College of Medical Genetics Board of Directors. Points to consider: ethical, legal, and psychosocial implications of genetic testing in children and adolescents. Am J Human Genet 1995;57:1233-1241.

9. Nelson RM, Botkin JR, Kodish ED, et al. Ethical issues with genetic testing in pediatrics. Pediatrics 2001;107:1451-1455.

10. British Medical Association Ethics Department. Medical Ethics Today: The BMAs Handbook of Ethics and Law, 3rd edn. Wiley-Blackwell: West Sussex, UK, 2012.

11. Borry P, Goffin T, Nys H, Dierickx K. Attitudes regarding carrier testing in incompetent children: a survey of European clinical geneticists. Eur J Hum Genet 2007;15:1211-1217.

12. Borry P, Goffin T, Nys H, Dierickx K. Attitudes regarding predictive genetic testing in minors: a survey of European clinical geneticists. Am J Med Genet C Semin Med Genet 2008;148C:78-83.

13. Acharya K, Ross LF. Fragile X screening: attitudes of genetic health professionals. Am J Med Genet A 2009;149A:626-632.

14. Campbell E, Ross LF. Professional and personal attitudes about access and confidentiality in the genetic testing of children: a pilot study. Genet Test 2003; 7:123-130

15. Fryer A. Inappropriate genetic testing of children. Arch Dis Child 2000;83:283-285.
16. Multhaupt-Buell TJ, Lovell A, Mills L, Stanford KE, Hopkin RJ. Genetic service providers' practices and attitudes regarding adolescent genetic testing for carrier status. Genet Med 2007;9:101-107.

17. Scott J, Marshall G. A Dictionary of Sociology. Oxford University Press: Oxford, UK, 2009. http://www.oxfordreference.com/views/ENTRY. html?subview=Main\&entry=t88.e2118.

18. Tremblay M. The key informant technique: a non-ethnographic application. In Burgess RG (ed). Field Research: A Sourcebook and Field Manual. George Allen \& Unwin: London, 1982.

19. Schamber L. Time-line interviews and inductive content analysis: their effectiveness for exploring cognitive behaviors. J Am Soc Inf Sci 2000;51:734744.

20. Downe-Wamboldt B. Content analysis: method, applications, and issues. Health Care Women Int 1992;13:313-321.

21. Graneheim UH, Lundman B. Qualitative content analysis in nursing research: concepts, procedures and measures to achieve trustworthiness. Nurse Educ Today 2004;24:105-112.

22. Balfour-Lynn I, Madge S, Dinwiddie R. Testing carrier status in siblings of patients with cystic fibrosis. Arch Dis Child 1995;72:167-168.

23. Barnes $C$. Testing children for balanced chromosomal translocations: parental views and experiences. In: Clarke AJ (ed). The Genetic Testing of Children. BIOS Scientific Publishers: Oxford, UK, 1998:51-60.

24. Brunger JW, Murray GS, O'Riordan M, Matthews AL, Smith RJ, Robin NH. Parental attitudes toward genetic testing for pediatric deafness. Am J Hum Genet 2000;67:1621-1625.

25. Fanos JH. The missing link in linkage analysis: the well sibling revisited. Genet Test 1999;3:273-278.

26. Massie RJ, Olsen M, Glazner J, Robertson CF, Francis I. Newborn screening for cystic fibrosis in Victoria: 10 years' experience (1989-1998). Med J Aust 2000;172:584-587.

27. Shapiro F, Specht L. The diagnosis and orthopaedic treatment of inherited muscular diseases of childhood. J Bone Joint Surg Am 1993;75: 439-454.

28. Nicole S, Diaz CC, Frugier T, Melki J. Spinal muscular atrophy: recent advances and future prospects. Muscle Nerve 2002;26:4-13.

29. Turner $G$, Webb T, Wake S, Robinson H. Prevalence of fragile X syndrome. Am J Med Genet 1996;64:196-197.

30. Lucassen A, Clancy T, Montgomery J, et al. Report on the Genetic Testing of Children. British Society for Human Genetics: Birmingham, UK, 2010.

31. Meldrum C, Scott C, Swoboda KJ. Spinal muscular atrophy genetic counseling access and genetic knowledge: parents' perspectives. J Child Neurol 2007;22:1019-1026.

32. McConkie-Rosell A, Spiridigliozzi GA, Rounds K, et al. Parental attitudes regarding carrier testing in children at risk for fragile X syndrome. Am J Med Genet 1999;82:206-211.

33. Liamputtong P, Ezzy D. Qualitative Research Methods. Oxford University Press: New York, 2005.

34. Duncan RE, Delatycki MB. Predictive genetic testing in young people for adultonset conditions: where is the empirical evidence? Clin Genet 2006;69:8-16; discussion 17.

35. Mand C, Gillam L, Duncan RE, Delatycki MB. "It was the missing piece": adolescent experiences of predictive genetic testing for adult-onset conditions. Genet Med 2013;15:643-649.

36. Clarke AJ, Flinter F. The genetic testing of children: a clinical perspective. In: Marteau T, Richards M (eds). The Troubled Helix. Cambridge University Press: Cambridge, UK, 1996: 164-176.

37. Järvinen $\mathrm{O}$, Aalto $A M$, Lehesjoki $A E$, et al. Carrier testing of children for two $X$ linked diseases in a family based setting: a retrospective long term psychosocial evaluation. J Med Genet 1999;36:615-620.

38. Järvinen $\mathrm{O}$, Lehesjoki $A E$, Lindlöf $M$, Uutela $A$, Kääriäinen $\mathrm{H}$. Carrier testing of children for two X-linked diseases: A retrospective study of comprehension of the test results and social and psychological significance of the testing. Pediatrics 2000;106:1460-1465.

39. Bobo JK, Kenneson A, Kolor K, Brown MA. Adherence to American Academy of Pediatrics recommendations for cardiac care among female carriers of Duchenne and Becker muscular dystrophy. Pediatrics 2009;123: e471-e475.

40. Street AM, Ljung R, Lavery SA. Management of carriers and babies with haemophilia. Haemophilia 2008;14(suppl 3):181-187. 